\title{
A bio-guided assessment of the anti-inflammatory activity of hop extracts (Humulus lupulus L. cv. Cascade) in human gastric epithelial cells
}

Enrico Sangiovanni ${ }^{\mathrm{a},}$, Marco Fumagalli ${ }^{\mathrm{a}}$, Laura Santagostini ${ }^{\mathrm{b}}$, Martino Forino ${ }^{\mathrm{c}}$, Stefano Piazza ${ }^{\mathrm{a}}$, Elisa Colombo ${ }^{\text {a }}$, Orazio Taglialatela-Scafati ${ }^{\mathrm{d}}$, Gelsomina Fico ${ }^{\mathrm{e}}{ }^{\mathrm{f}}$, Mario Dell'Agli ${ }^{\mathrm{a}}$

aDepartment of Pharmacological and Biomolecular Sciences, Università degli Studi di Milano, Via Balzaretti 9, 20133 Milan, Italy

bDepartment of Chemistry, Università degli Studi di Milano, Via Golgi 19, 20133 Milan, Italy

${ }^{c}$ Department of Agricultural Sciences, University of Naples Federico II, Enology Sciences Section, Viale Italia, 83100 Avellino, Italy

${ }^{d}$ Department of Pharmacy, University of Naples Federico II, Via Montesano 49, 80131 Naples, Italy eDepartment of Pharmaceutical Sciences, Università degli Studi di Milano, Via Mangiagalli 25, 20133 Milan, Italy

fBotanic Garden GE Ghirardi, Department of Pharmaceutical Sciences, Università degli Studi di Milano, Via Religione 25, I-25088 Toscolano Maderno (BS), Italy

Corresponding author at: Department of Pharmacological and Biomolecular Sciences, Università degli Studi di Milano, Via Balzaretti 9, 20133 Milan, Italy E-mail address: enrico.sangiovanni@unimi.it (E. Sangiovanni). 


\begin{abstract}
The present work aims to characterize and investigate the anti-inflammatory activity of hop extracts (cv. Cascade) in an in vitro model of gastric inflammation. The biological activities of hydroalcoholic and aqueous extracts from cones were evaluated by comparing IL-8 inhibition induced by TNF $\alpha$. The hydroalcoholic extract demonstrated a higher inhibitory effect, which was just slightly affected by an in vitro simulated gastric digestion. The identification of active compounds was performed by a bioguided fractionation which afforded 11 fractions, one of which inhibited IL-8 release in a concentration-dependent fashion in human gastric epithelial AGS cells. Phytochemical analysis revealed xanthohumol $\mathrm{A}$ and xanthohumol $\mathrm{D}$ as the main active components. The present study provides some experimental evidences that Humulus lupulus L. may exert an anti-inflammatory activity on the gastric district by the inhibition of the IL-8 secretion, partially due to its prenylated chalcones content.
\end{abstract}

\title{
Keywords
}

Hop, Humulus lupulus L., Gastric inflammation, IL-8, Xanthohumol, AGS cells.

\section{Highlights}

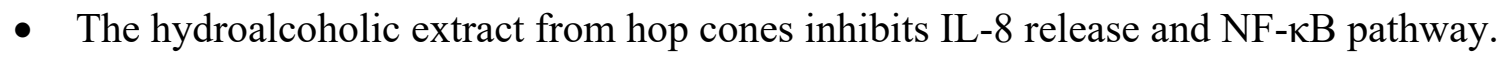

- In vitro gastric digestion of hop extract slightly alters biological activity.

- Chalcones may act as major contributors to the anti-inflammatory activity.

- First demonstration of the anti-inflammatory activity of xanthohumol D in AGS cells. 


\section{Graphical abstract}

Humulus lupulus L.

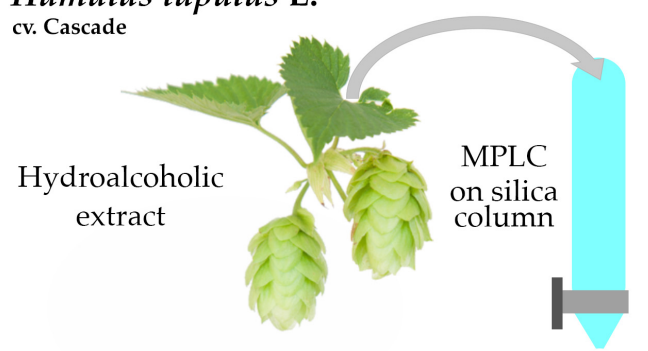

Gastric epithelial cells

TNF $\alpha$
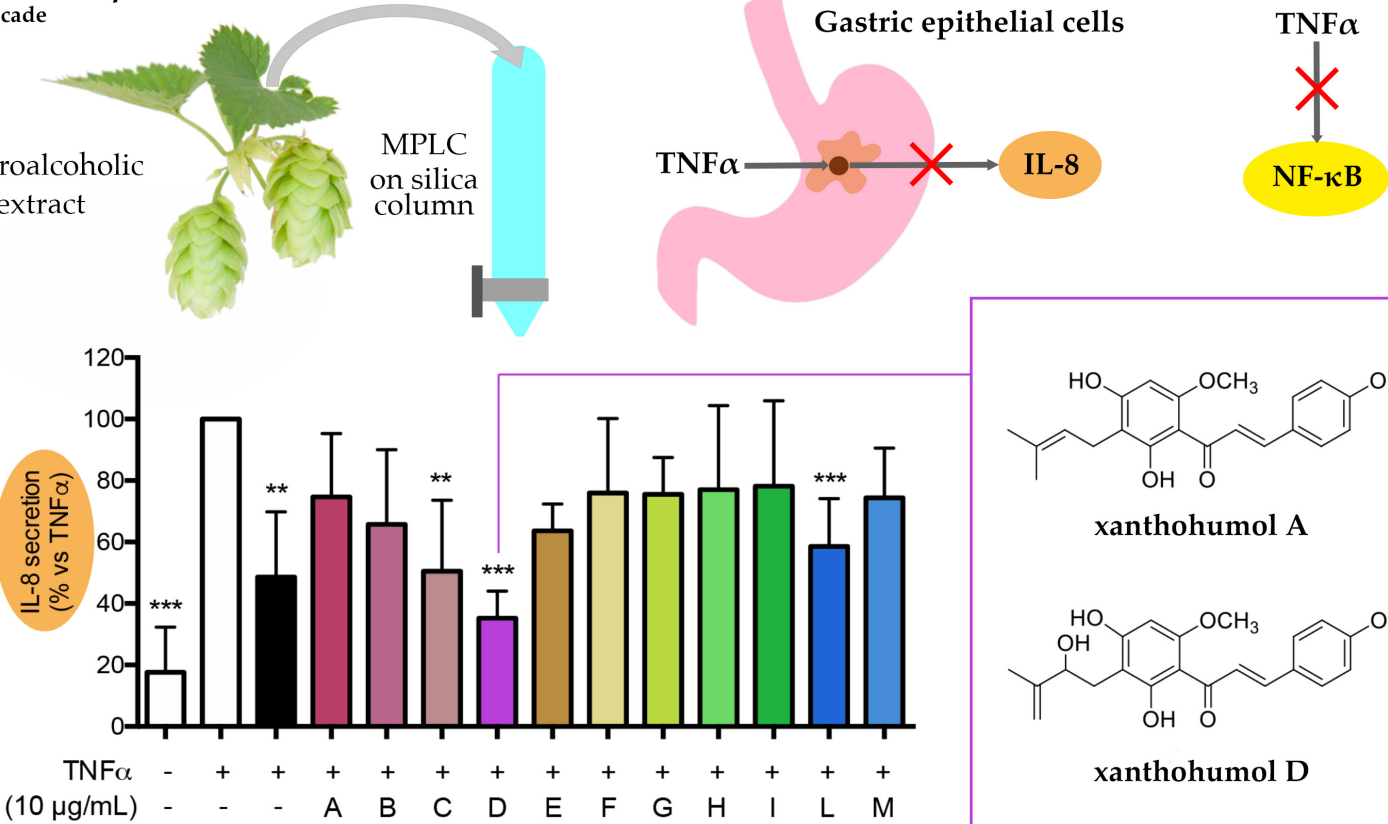

raction $(10 \mu \mathrm{g} / \mathrm{mL})$

$$
(10 \mu \mathrm{g} / \mathrm{mL})
$$

n-hexane

EtOAc

$\mathrm{MeOH}$

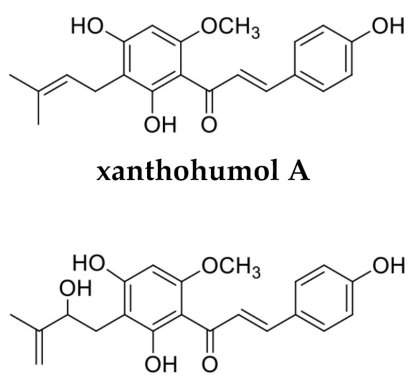

xanthohumol D 


\section{Introduction}

Chronic gastritis is a common disease which represents an important background for the development of several gastric pathologies. Some of the most serious consequences of a prolonged inflammation at gastric level are peptic ulcers (Chuah et al., 2014) and cancer (Chen et al., 2016; Ohata et al., 2004). Despite a decline in the incidence in the past decades, stomach cancer has been estimated in more than 1,000,000 new cases and responsible for 783,000 deaths worldwide just in 2018 (Bray et al., 2018). Helicobacter pylori infection represents a major risk factor in this context (Chen et al., 2016), since this Gram negative bacterium colonizes the gastric mucosa of over $50 \%$ of the world human population (Rugge et al., 2011) and induces a persistent immune response in the host (Crabtree, 1996), which is characterized by the release of several inflammatory cytokines in the gastric mucosa, including IL-8 and TNF $\alpha$ (Crabtree, Shallcross, Heatley, \& Wyatt, 1991; Gionchetti et al., 1994; Moss, Legon, Davies, \& Calam, 1994; Noach et al., 1994). When exposed to TNF $\alpha$, gastric epithelial cells release IL-8, a potent chemokine promoting neutrophil infiltration (Crabtree et al., 1994; Sharma, Tummuru, Miller, \& Blaser, 1995; K Yasumoto et al., 1992), through activation of NF- $\kappa B$ (Choi et al., 2006; K Yasumoto et al., 1992), a transcription factor deeply involved in the inflammatory processes (Barkett \& Gilmore, 1999; Bonizzi \& Karin, 2004; Shishodia \& Aggarwal, 2004). IL-8 levels in the gastric mucosa has been positively associated with the severity of gastritis (Xuan et al., 2005) and the serum levels of this chemokine correlate with the degree of gastric chronic inflammation and neutrophil infiltration (Siregar, Halim, \& Sitepu, 2015), making this molecule an ideal marker to evaluate the gastric inflammatory state. Since IL-8 contributes to the amplification of the inflammation, the search for new extracts or natural leads able to inhibit this chemokine could be a strategy to prevent more severe clinical outcomes.

Hops (Humulus lupulus L., Cannabaceae) is a plant extensively used in human nutrition, in particular for the production of beer, in which the female inflorescences are used to provide the typical bitterness and aroma. Despite the consumption of beer is not recommended for human gastric inflammation, due to its alcohol content and relative pro-oxidant effects (de Gaetano et al., 2016), hops, as ingredients of food supplements, are considered an interesting source of bioactive compounds, such as xanthohumol A (Figure 1A), a prenylated chalcone that has shown anti-inflammatory activity in different experimental models (Cho et al., 2008; Dorn, Heilmann, \& Hellerbrand, 2012; Dorn, Kraus, et al., 2010; Lee et al., 2011). The consumption of hop-based products is increasing, and hops are not only ingredients in food supplements, but also important component of non-alcoholic beverages. There is a particular interest in the research of hops active components; despite the high consumption of hops in human diet, only few studies investigated their possible beneficial effects at the gastric 
level.
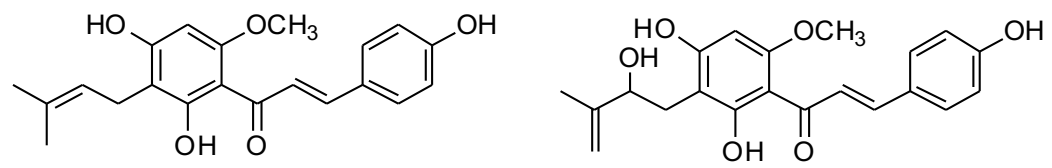

Figure 1. Chemical structures of xanthohumol A (left) and xanthohumol D (right).

The intragastric administration of a commercial hop dry extract in a rat pylorus-ligated model increased gastric juice volume without affecting acidity, a mechanism mediated by cholinergic nervous system that could positively affect the digestion process (Kurasawa, Chikaraishi, Naito, Toyoda, \& Notsu, 2005). Two studies described the effect of hops against Helicobacter pylori. In the first study, fresh hops homogenates from three different varieties inhibited in vitro the growth of a clinical isolated bacterium and the effect was partly attributed to their content in $\alpha$ - and $\beta$-acids (Cermak et al., 2015). In the second study, a high molecular weight fraction from hop bract extract, rich in polymerized catechins, reduced in mice the gastric damage induced by the oral administration of VacA, a vacuolating cytotoxin produced by Helicobacter pylori (Yahiro et al., 2005)(Yahiro et al., 2005)(Yahiro et al., 2005)(Yahiro et al., 2005). As anti-inflammatory effects, a $\mathrm{CO}_{2}$ hop extract reduced the prostaglandin $\mathrm{E}_{2}$ production in adenocarcinoma gastric cells (AGS) by influencing COX2 enzyme (Tripp et al., 2005), while xanthohumol A suppressed the proliferation, apoptosis and metastasis of AGS cells via induction of ROS production and inhibition of the NF- $\kappa$ B signaling (Wei et al., 2018).

In a previous study by our group, the hop cultivar Cascade, a highly appreciated cultivar, was phytochemically characterized with the discovery of three new minor constituents, 4hydroxycolupulone, humudifucol, and cascadone (Forino et al., 2016). In addition, xanthohumol A was found to inhibit the activity of two important pro-inflammatory enzymes, microsomal prostaglandin $E_{2}$ synthase (mPGES)-1 and 5-lipoxygenase (5-LO) (Forino et al., 2016).

On these bases, the present work aimed at deepening the investigation on the anti-inflammatory potential of $\mathrm{cv}$. Cascade hop in gastric epithelial cells, possibly identifying the molecule(s) responsible for the effect. Attention has been paid to the extract ability to inhibit IL- 8 release by

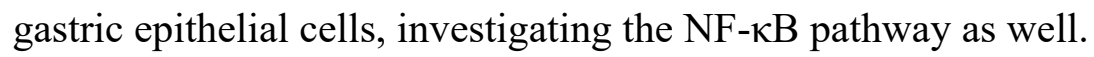

\section{Material and methods}

\subsection{General Experimental Procedures}


Dulbecco's Modified Eagle's Medium/F12 (DMEM)/F12 (1:1), penicillin, streptomycin, Lglutamine and trypsin-EDTA were from Gibco (Life Technologies Italia, Monza, Italy). Foetal bovine serum (FBS), and disposable materials for cell culture were purchased by Euroclone (Euroclone S.p.A., Pero-Milan, Italy). Human adenocarcinoma cells (AGS, CRL-1739) were purchased from LGC Standard S.r.1., Milano, Italy.

The reagent 3-(4,5-dimethylthiazol-2-yl)-2,5-diphenyltetrazolium bromide (MTT) and curcumin were from Sigma Aldrich (Milan, Italy). All reagents used for the biological assays were HPLC grade. Human TNF $\alpha$ and Human IL-8 Elisa Development Kit were from Peprotech Inc. (London, UK). All chromatographic solvents were HPLC grade or LC-MS grade for MS experiments. Acetonitrile, methanol, ethanol, formic acid, hydrochloric acid, vanillin, and iron sulfate were from Sigma Aldrich (Milan, Italy).

NMR experiments were run on Varian Unity Inova 700 spectrometer equipped with a ${ }^{13} \mathrm{C}$ Enhanced HCN Cold Probe and by using a Shigemi $5 \mathrm{~mm}$ NMR tubes. HPLC-RI separations were performed on a Knauer (Berlin, Germany) 1800 apparatus equipped with a refractive index detector.

\subsection{Plant material}

Hop plantlets were purchased at Garten Eickelmann (Geisenfeld, Germany) and cultivated for four years in an experimental site (Farm La Morosina, Abbiategrasso, Milan, Italy) and collected in 2014. Cones, collected at maturity, were dried at $40^{\circ} \mathrm{C}$ in a thermostatic room, protected from light. A voucher specimen was deposited at the Herbarium of the Botanical Garden GE Ghirardi, Department of Pharmaceutical Sciences, University of Milan, with number Hl 101.

\subsection{Preparation of the extracts}

Before extraction, hop cones were kept at $4^{\circ} \mathrm{C}$ to limit the chemical and enzymatic reactions. Subsequently the drug (20 g) was dried in an oven at $40^{\circ} \mathrm{C}$ for 24 hours and, the following day, the dried cones were pulverized using a mortar and a pestle. The obtained powder was stored inside an amber glass bottle at $4^{\circ} \mathrm{C}$. To obtain the extracts, 3 grams of powder were extracted twice with 30 $\mathrm{mL}$ of water (aqueous extract) or $30 \mathrm{~mL}$ of ethanol/water 50:50 (hydroalcoholic extract) for 4 and 16 hours, respectively, at room temperature under dark conditions. The mixture was filtered through Supervelox filter paper to remove plant debris; solvents were evaporated using a Rotavapor system and extracts containing water were frozen with dry ice and alcohol and placed at $-80^{\circ} \mathrm{C}$ overnight, then lyophilized and maintained at $-20^{\circ} \mathrm{C}$. The yields $(\mathrm{w} / \mathrm{w})$ of each extraction were calculated as percentage ratio between the dried extract weight and the weight of the fresh starting material. Stock solutions of the extracts were prepared, aliquoted at $25 \mathrm{mg} / \mathrm{mL}$ and kept at $-20^{\circ} \mathrm{C}$; aqueous extract 
was solved in a mixture of water/DMSO (50:50), while hydroalcoholic extract used an ethanol/water mixture (50:50).

\subsection{Fractionation of the hydroalcoholic extract}

A sample of the inflorescences of H. lupulus cultivar Cascade (30 g), was triturated and extracted three times with $500 \mathrm{~mL}$ of $\mathrm{H}_{2} \mathrm{O}$ or with $500 \mathrm{~mL}$ of EtOH/ $\mathrm{H}_{2} \mathrm{O}(1: 1)(\mathrm{v} / \mathrm{v})$ mixture. The extracts were combined and evaporated, and the resulting residue was separated on a MPLC (Buchi) silica gel (230-400 mesh) column $(460 \mathrm{~mm} \times 70 \mathrm{~mm})$ eluted with a stepwise gradient of $n$-hexane to EtOAc and then to $\mathrm{MeOH}$. The polarity was changed from $n$-hexane to EtOAc by increasing the EtOAc percentages by $10 \%(\mathrm{v} / \mathrm{v})$, after each $250 \mathrm{~mL}$, and then by EtOAc to $\mathrm{MeOH}$ with a $30 \%(\mathrm{v} / \mathrm{v})$ increase. Following this procedure, 11 fractions were collected (A-M): A (375 mg), B (120 mg), C (68 mg), D (75 mg), E (121 mg), F (90 mg); G (77 mg), H (89 mg), I (111 mg), L (221 mg), M (300 mg). The most active fraction, fraction D (75 mg, 0.25\%), was further purified on a HPLC equipped with RI detector and a Gemini $10 \mu \mathrm{m}$ column and eluted with $\mathrm{H}_{2} \mathrm{O}-\mathrm{MeOH}(2: 8)$ to obtain pure xanthohumol A (59 mg, 0.20\%) and xanthohumol D (6.8 mg, 0.023\%) (Figure 1B).

\subsection{HPLC-DAD and LC-MS analysis}

HPLC-DAD analyses of samples obtained from hydroalcoholic extraction were performed at room temperature on a Jasco PU 1580 HPLC system, equipped with MD-1510 PDA detector and Lichrocart® RP-18 column ( 250 x 4.6 mm, $3 \mu \mathrm{m}$, Merck KGaA, Darmstadt, Germany). A binary mixture composed of $0.1 \%$ formic acid in water (A) and pure acetonitrile (B) was used for elution, applying the following gradient program: 0-10 min B 10-15\%, 10-45 $\min$ B 15-40\%, 45-52 $\min \mathrm{B}$ $40-100 \%$ and $52-58 \mathrm{~min} \mathrm{~B} 100 \%$, at a flow rate of $0.6 \mathrm{~mL} / \mathrm{min}$. LC-MS analyses were performed on a Thermo Finnigan LC-MS system, equipped with a PDA detector and an LCQ Advantage (ESI+ ionization, fleet ion trap) mass spectrometer, using the same column and gradient conditions reported above. Evaluation of xanthohumol concentrations were performed by comparison with known solutions of each pure xanthohumol isomer, obtained by further purification of hop extract (Forino et al., 2016). LC-ESI-MS conditions for analysis were: Capillary Temperature $275^{\circ} \mathrm{C}$, Source Heater Temperature $150^{\circ} \mathrm{C}$, Sheath Gas Flow 20.0 (Arb.Unit), Aux Gas Flow 10.0 (Arb.Unit), Source voltage 4 kV, Source Current $100 \mathrm{uA}$, Capillary Voltage $50 \mathrm{~V}$.

\subsection{Cytotoxicity}

The integrity of the cell morphology before and after treatment was assessed by light microscope inspection. Cell viability was measured, after $6 \mathrm{~h}$ treatment, by the 3,4,5-dimethylthiazol-2-yl-2-5- 
diphenyltetrazolium bromide (MTT) method. This method evaluates the activity of a mitochondrial enzyme, which is an index of cell viability. The concentrations of the extracts which resulted cytotoxic were excluded from other biological assays.

\subsection{Cell culture and IL-8 release measurement}

AGS cells were grown at $37^{\circ} \mathrm{C}$ in DMEM F12 supplemented with 100 units penicillin per mL, $100 \mathrm{mg}$ streptomycin per mL, $2 \mathrm{mM}$ L-glutamine, and 10\% heat-inactivated FBS (Euroclone S.p.A, Pero, Italy), under a humidified atmosphere containing $5 \% \mathrm{CO}_{2}$.

Cells were grown in 24-well plates for $48 \mathrm{~h}$ (30,000 cells per well) before the cytokine treatment. The IL-8 secretion, induced by TNF $\alpha$ at $10 \mathrm{ng} / \mathrm{mL}$, was tested after $6 \mathrm{~h}$ treatment in the presence of un-digested or digested extracts $(0.1-50 \mu \mathrm{g} / \mathrm{mL})$. EGCG $(10 \mu \mathrm{M})$ was used as the reference inhibitor (Bulgari et al., 2012; Fumagalli et al., 2016) of IL-8 secretion (50\% inhibition). IL-8 was quantified using a Human Interleukin-8 ELISA Development Kit as described below. Briefly, Corning 96 well EIA/RIA plates from Sigma- Aldrich (Milan, Italy) were coated with the antibody provided in the ELISA Kit (Peprotech Inc., London, UK) overnight at $4{ }^{\circ} \mathrm{C}$. After blocking the reaction, $200 \mu 1$ of samples in duplicate were transferred into wells at room temperature for $1 \mathrm{~h}$. The amount of IL-8 in the samples was detected by spectroscopy (signal read: $450 \mathrm{~nm}, 0.1 \mathrm{~s}$ ) by the use of biotinylated and streptavidin-HRP conjugate antibodies, evaluating the 3,3',5,5'-tetramethylbenzidine (TMB) substrate reaction. Quantification of IL-8 was done using an optimized standard curve supplied with the ELISA Kit $(8.0-1000.0 \mathrm{pg} / \mathrm{mL})$.

\subsection{Transient transfection assay}

To evaluate the NF-אB driven transcription and IL-8 promoter activity, AGS cells were plated in 24-well plates (30,000 cells per well); after 48 hours, cells were transfected by the calcium-phosphate method with $100 \mathrm{ng}$ per well of native IL-8-LUC or $50 \mathrm{ng}$ per well of NF-kB-LUC, the latter containing the luciferase reporter gene under the control of a NF- $\kappa \mathrm{B}$ responsive promoter (E-selectin promoter). The plasmid NF-кB-LUC was a gift of Dr. N. Marx (Department of Internal MedicineCardiology, University of Ulm, Ulm, Germany). After $16 \mathrm{~h}$, the cells were treated with the stimulus (TNF $\alpha 10 \mathrm{ng} / \mathrm{mL})$ and the extract for $6 \mathrm{~h}$. EGCG $(10 \mu \mathrm{M})$ was used as the reference inhibitor $(75 \%$ inhibition for NF-kB-LUC driven transcription). At the end of this time, cells were lysed, and the luciferase assay was performed using the Britelite ${ }^{\mathrm{TM}}$ Plus reagent (PerkinElmer Inc., Walthman, MA, USA) according to the manufacturer's instructions. Data were expressed considering $100 \%$ of the luciferase activity related to the cytokine-induced promoter activity. 


\subsection{Evaluation of $N F-\kappa B$ nuclear translocation}

For the NF- $\mathrm{kB}$ (p65) nuclear translocation assay, AGS cells were plated at the concentration of $1.5 \times 10^{6}$ cells $/ \mathrm{ml}$ in $60-\mathrm{mm}$ plates. After 48 hours, cells were treated for 1 hour with the inflammatory mediator (TNF $10 \mathrm{ng} / \mathrm{mL}$ ) and the extracts under study. Nuclear extracts were prepared using Nuclear Extraction Kit from Cayman Chemical Company (Michigan, USA) and stored at $-80^{\circ} \mathrm{C}$ until assayed. The same quantity of total nuclear proteins, measured by Bradford assay, was used to assess $\mathrm{NF}-\kappa \mathrm{B}$ nuclear translocation using the NF- $\mathrm{B}$ (p65) transcription factor assay kit (Cayman), followed by spectroscopy analysis (signal read $450 \mathrm{~nm}, 0.1 \mathrm{~s}$ ). Data were expressed considering 100\% the absorbance related to the cytokine-induced NF- $\mathrm{B}$ nuclear translocation. EGCG $(10 \mu \mathrm{M})$ was used as the reference inhibitor ( $85 \%$ inhibition for NF- $\mathrm{kB}$ nuclear translocation).

\subsection{Simulated in vitro gastric digestion}

According to a well-established protocol, the gastric digestion was simulated using an in vitro approach previously described (Sangiovanni et al., 2015). Briefly, the extract (100 mg) was incubated for 5 minutes at $37^{\circ} \mathrm{C}$ with $6 \mathrm{~mL}$ of saliva juice, then $12 \mathrm{~mL}$ gastric juice were added to the suspension and the sample was incubated for 2 hours at $37^{\circ} \mathrm{C}$. At the end of the incubation, the digested sample was centrifuged for 5 minutes at $3000 \mathrm{~g}$ and the supernatant frozen and lyophilized. All the samples, at different steps, were then stored at $-20^{\circ} \mathrm{C}$ until the use for biological assays.

\subsection{Statistical Analysis}

All data are expressed as mean \pm s.d.; data were analyzed by unpaired one-way analysis of variance (ANOVA) followed by Bonferroni as post-hoc test. Statistical analyses were done using GraphPad Prism 5.0 software (GraphPad Software Inc., San Diego, CA, USA) by comparing all the conditions with respect to the stimulated control $(\mathrm{TNF} \alpha)$, considering $* \mathrm{p}<0.05 ; * *_{\mathrm{p}}<0.01$ and $* * * \mathrm{p}<0.001$. The value of $\mathrm{p}<0.05$ was considered statistically significant. IC $_{50}$ was calculated using GraphPad Prism 5.00 software.

\section{Results and Discussion}

Dried inflorescence powder of Humulus lupulus cv. Cascade was extracted with two different solvent mixtures, water (aqueous extract) and ethanol/water (50:50) (hydroalcoholic extract), two solvents suitable for human consumption, and the yields of extraction were respectively $19.66 \%$ and $29.96 \%$. Both the extracts preliminarily revealed lack of cytotoxicity on the gastric cell model (AGS), till the maximal concentration tested of $100 \mu \mathrm{g} / \mathrm{mL}$ (data shown in supplementary materials, Figure S1). In order to evaluate the potential anti-inflammatory effects of hops, cells were challenged with TNF $\alpha$ in the presence of different concentrations of extract. As shown in Figure 2A, the hydroalcoholic 
extract inhibited the release of IL-8 in a concentration dependent manner, with an $\mathrm{IC}_{50}$ of $3.95 \mu \mathrm{g} / \mathrm{mL}$, while the aqueous extract did not show any inhibitory effect till the highest concentration tested of $50 \mu \mathrm{g} / \mathrm{mL}$. On the contrary, when a reporter plasmid containing the IL-8 promoter region was used, both the extracts were active, completely inhibiting the effect of $\mathrm{TNF} \alpha$ at $10 \mu \mathrm{g} / \mathrm{mL}$. IC 50 values revealed that the hydroalcoholic extract was slightly more active compared to the aqueous one $(2.34$ and $3.59 \mu \mathrm{g} / \mathrm{mL}$, respectively) and this effect was obtained in the same range of the protein release inhibition (Figure 2B).

To investigate the molecular mechanism underlying the effects observed on IL-8, we investigated the ability of hop extracts to impair the NF- $\mathrm{KB}$ pathway. This transcription factor plays a central role in regulating IL-8 gene in several cell models, including gastric epithelial cells. Hop extracts reduced the transcription of the luciferase gene controlled by NF- $\mathrm{BB}-\mathrm{LUC}$ plasmid, which contains a promoter region strictly dependent on the $\mathrm{NF}-\mathrm{\kappa B}$, and the effect was obtained in a range of concentrations comparable to those described with IL-8-LUC. Hydroalcoholic extract reduced the transcription with $\mathrm{IC}_{50}$ of $2.44 \mu \mathrm{g} / \mathrm{mL}$, similarly to the aqueous extract ( $\mathrm{IC}_{50} 2.25 \mu \mathrm{g} / \mathrm{mL}$ ) as shown in Figure $3 \mathrm{~A}$. Surprisingly, the effect of the extracts on the inhibition of the NF- $\kappa B$ nuclear translocation, a former step in the inflammatory activation, required higher concentrations to be achieved.

Hydroalcoholic

Aqueous
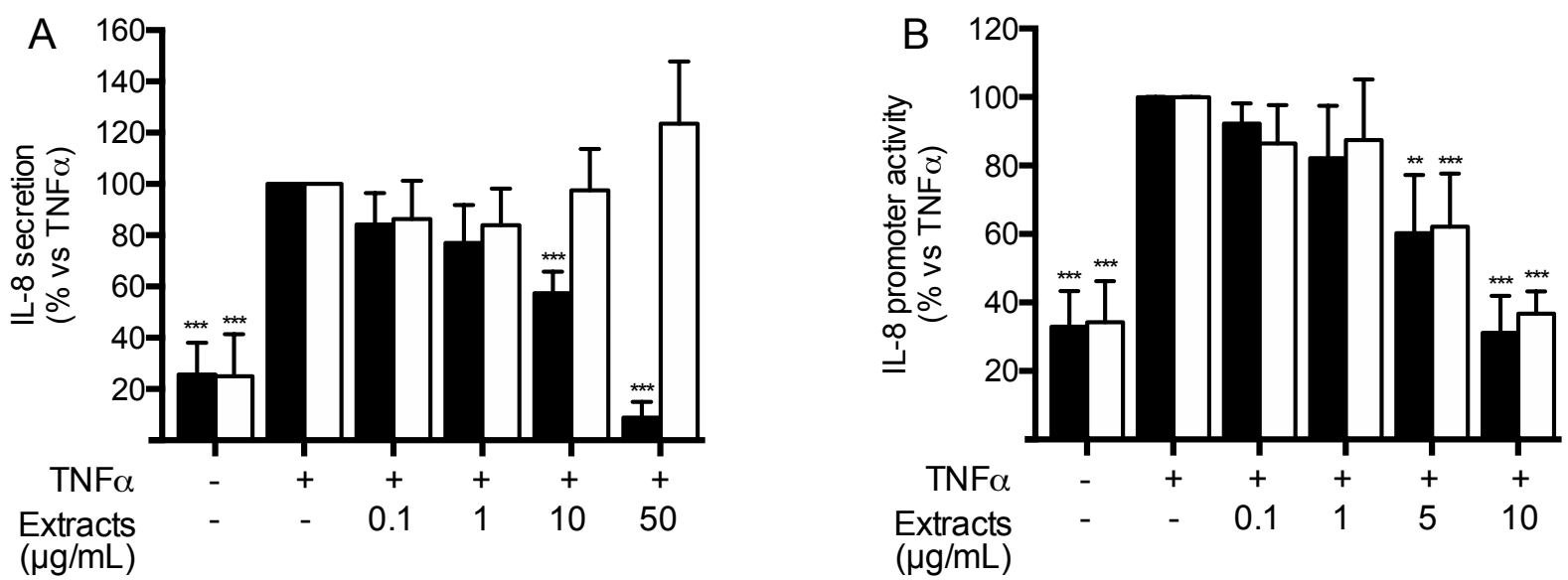

Figure 2. Inhibitory effect of the hydroalcoholic (black bars) and aqueous (white bars) extracts on IL-8 release induced by TNF $\alpha$ in gastric epithelial cells (A), in comparison to their effect on IL-8 promoter activity (B), measured by the use of a reporter plasmid regulated by IL-8 promoter region. Results are expressed as percentage of the TNF $\alpha$ stimulated condition. EGCG (10 $\mu \mathrm{M})$ was used as the reference inhibitor (50\% inhibition of IL-8 secretion and 15\% for IL- 8 promoter activity). 
As depicted in Figure 3B, only the highest concentration tested $(100 \mu \mathrm{g} / \mathrm{mL})$ brought the amount of nuclear NF- $\mathrm{KB}$ close to the level of the unstimulated control. In this case, both the extracts required more than ten times higher concentrations to impair NF- $\kappa \mathrm{B}$ translocation, compared to the inhibitory effect shown on NF- $\kappa$ B driven transcription, resulting in $\mathrm{IC}_{50} \mathrm{~S}$ of 33.88 and $42.32 \mu \mathrm{g} / \mathrm{mL}$, respectively for hydroalcoholic and aqueous extracts.

Hydroalcoholic

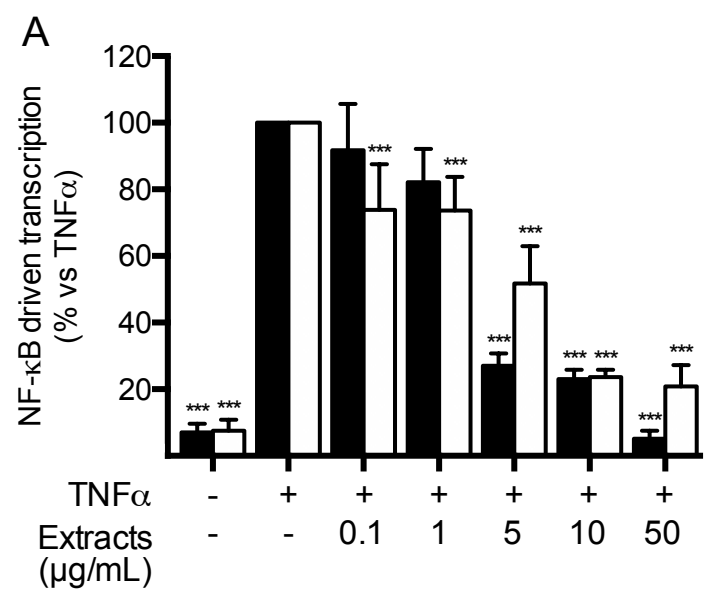

Aqueous

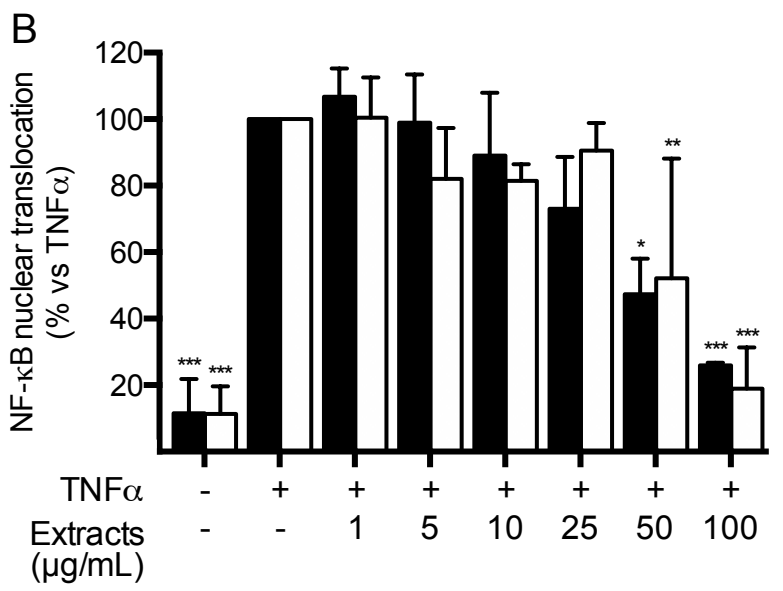

Figure 3. Inhibitory effect of the hydroalcoholic (black bars) and aqueous (white bars) extracts from hop on NF- $\kappa B$ driven transcription (A) and their effect on NF- $\kappa B$ nuclear translocation (B), both induced by TNF $\alpha$ in gastric epithelial cells. Results are expressed as percentage of the TNF $\alpha$ stimulated condition. EGCG $(10 \mu \mathrm{M})$ was used as the reference inhibitor $(75 \%$ inhibition for NF- $\mathrm{kB}$ LUC driven transcription and $85 \%$ for nuclear translocation).

These results suggest that hop extracts have the potential to inhibit NF- $\kappa B$ mostly by affecting the gene transcription mediated by this factor.

Even if the effect of the extracts was comparable when administered simultaneously to TNF $\alpha$, except for IL-8 secretion, the situation appeared different when extracts were used as pre-treatment. Although both generally less effective, hydroalcoholic extract applied for 1 hour before the inflammatory stimulus was more active in reducing the IL-8 promoter activity (Figure 4A) and the NF- $\kappa \mathrm{B}$ driven transcription (Figure 4B) ( $\mathrm{IC}_{50 \mathrm{~S}}$ of $9.60 \mu \mathrm{g} / \mathrm{mL}$ and $8.11 \mu \mathrm{g} / \mathrm{mL}$, respectively) in comparison to the aqueous one ( $\mathrm{IC}_{50} \mathrm{~s}$ of $34.91 \mu \mathrm{g} / \mathrm{mL}$ and $36.82 \mu \mathrm{g} / \mathrm{mL}$, respectively). However, onehour pre-treatment with the hydroalcoholic extract did not inhibit IL-8 release, even at the maximal concentration tested $(50 \mu \mathrm{g} / \mathrm{mL})$ as shown in Figure $4 \mathrm{C}$. As expected, the aqueous extract was inactive as well. 
A

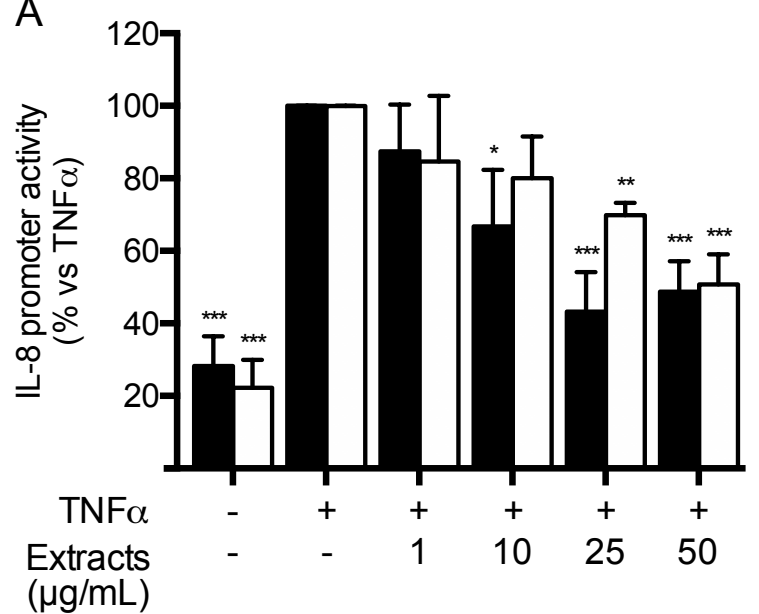

C

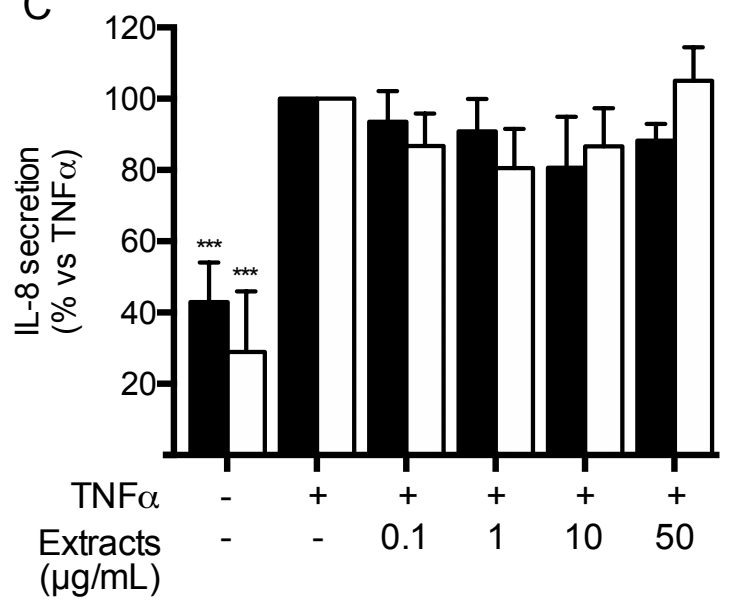

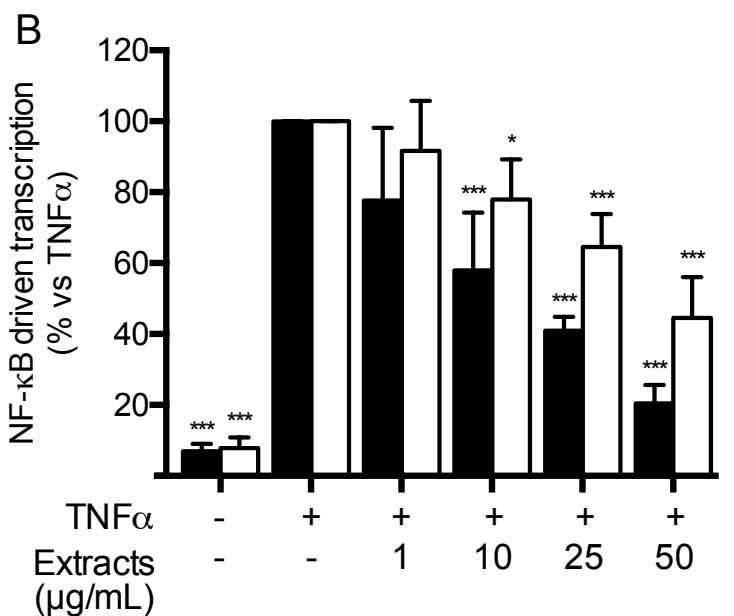

$\mathrm{D}$

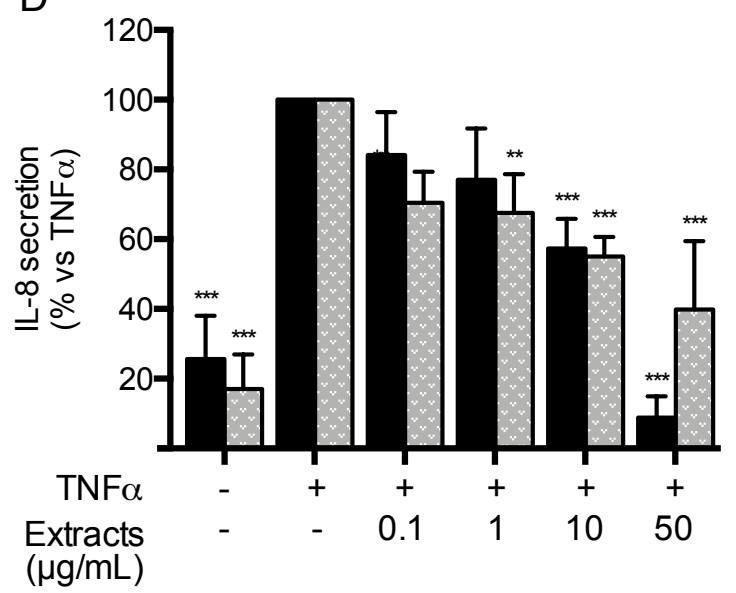

Figure 4. Inhibitory effect of one-hour pretreatment of hydroalcoholic (black bars) and aqueous (white bars) extracts from hop on IL-8 promoter activity (A), NF- $\kappa B$ driven transcription (B) and IL8 secretion (C), induced by TNF $\alpha$ in gastric epithelial cells. Effect on IL- 8 secretion of the simulated gastric digestion protocol applied to hydroalcoholic extract (grey bars) in comparison with the nondigested hydroalcoholic extract (black bar), measured during TNF $\alpha$ co-treatment (D). Results are expressed as percentage of the TNF $\alpha$ stimulated condition. EGCG $(10 \mu \mathrm{M})$, one-hour pretreatment, was used as the reference inhibitor (42\% inhibition for IL-8 secretion, 50\% inhibition for NF- $\mathrm{kB}-$ LUC driven transcription and 18\% for IL-8 promoter activity).

On the basis of the previous results, the hydroalcoholic extract resulted the most promising for the anti-inflammatory activity at gastric level and it was selected for further investigations. Since gastric environment may alter the bioactivity of compounds occurring in the extract, due to low $\mathrm{pH}$ and the presence of digestive enzymes, we investigated the effect of an in vitro simulated gastric digestion 
on the bioactivity of the hydroalcoholic extract. The digested extract was then evaluated on IL-8 release inhibition, as the final step of the inflammatory cascade. As evident in Figure 4D, the simulated gastric digestion showed only slight alteration of the activity of the hydroalcoholic extract, increasing the $\mathrm{IC}_{50}$ of IL-8 inhibition from $3.95 \mu \mathrm{g} / \mathrm{mL}$ to $6.40 \mu \mathrm{g} / \mathrm{mL}$. This result strengthens the possibility of using the hydroalcoholic extract from cv. Cascade hop as anti-inflammatory agent at gastric level.

As expected, the hydroalcoholic extract is a complex mixture of secondary metabolites (Figure 5A and 5B). According to mass spectral data and data reported in literature (Li and Deinzer 2007; Magalhaes et al. 2010), some major peaks were assigned as follows: 1) Procyanidin (epicatechin/catechin); 2) Quercetin-3-O-rutinoside; 3) Apigenin-6,8-di-C-glucoside; 4) Quercetin3-O-hexoside; 5) Kaempferol-3-O-rutinoside; 6) Quercetin-3-O-(6"'-malonyl) glucoside; 7) Kaempferol-3-O-hexoside; 8) Kaempferol-3-O-(6"'-malonyl) glucoside; 9) Xanthohumol D; 10) Xanthohumol A. In particular, xanthohumol A and xanthohumol D corresponded to $1.86 \%$ and $0.28 \%$ of the hydroalcoholic extract. 

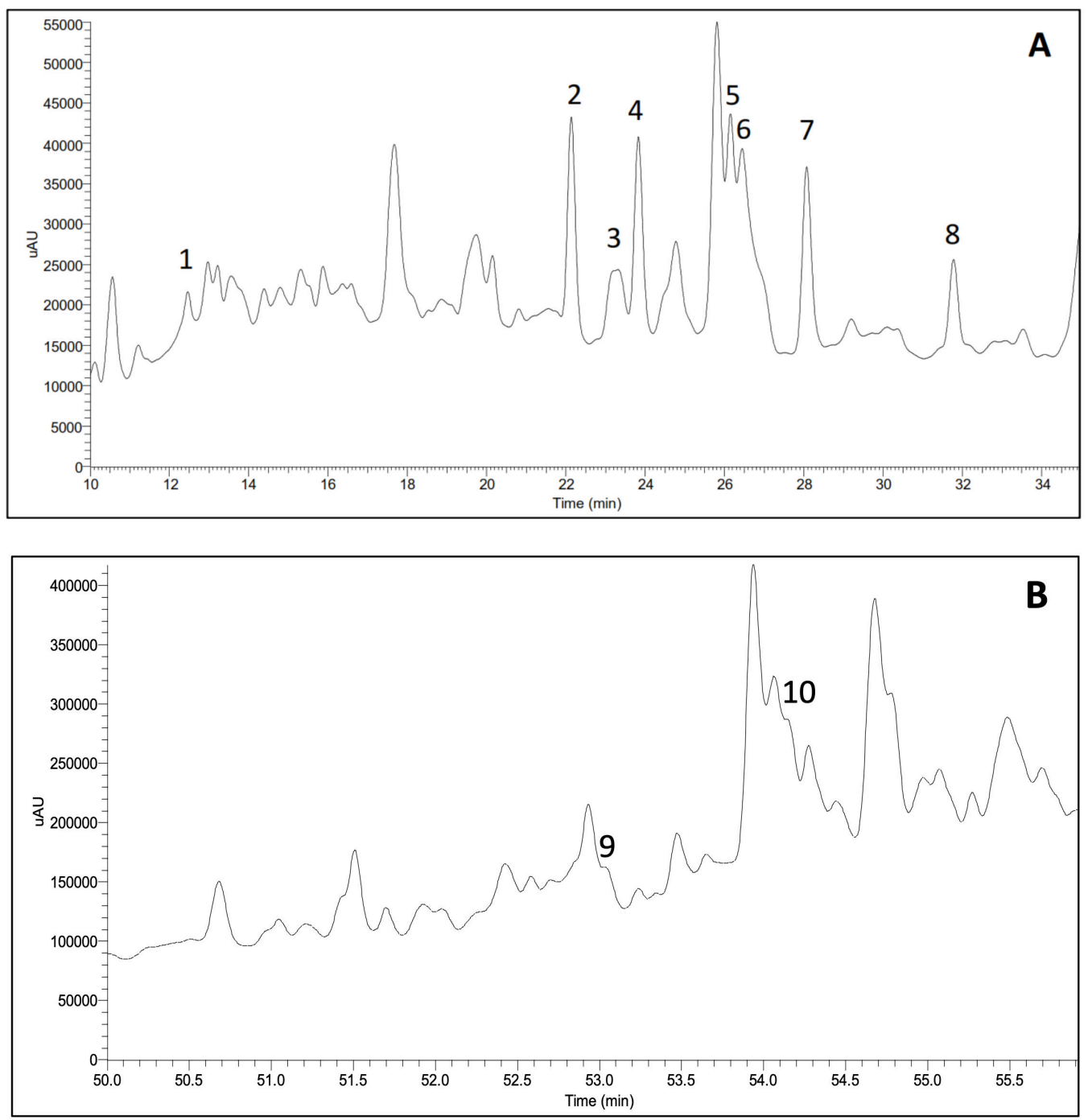

Figure 5. HPLC-UV profile of the hydroalcoholic extract: flavonoid (A) and prenylflavonoid region (B). According to mass spectral data and data reported in literature, peaks were assigned as follows: 1) Procyanidin (epicatechin/catechin); 2) Quercetin-3-O-rutinoside; 3) Apigenin-6,8-di-C-glucoside; 4) Quercetin-3-O-hexoside; 5) Kaempferol-3-O-rutinoside; 6) Quercetin-3-O-(6''-malonyl) glucoside; 7) Kaempferol-3-O-hexoside; 8) Kaempferol-3-O-(6''-malonyl) glucoside; 9) Xanthohumol D; 10) Xanthohumol A. 


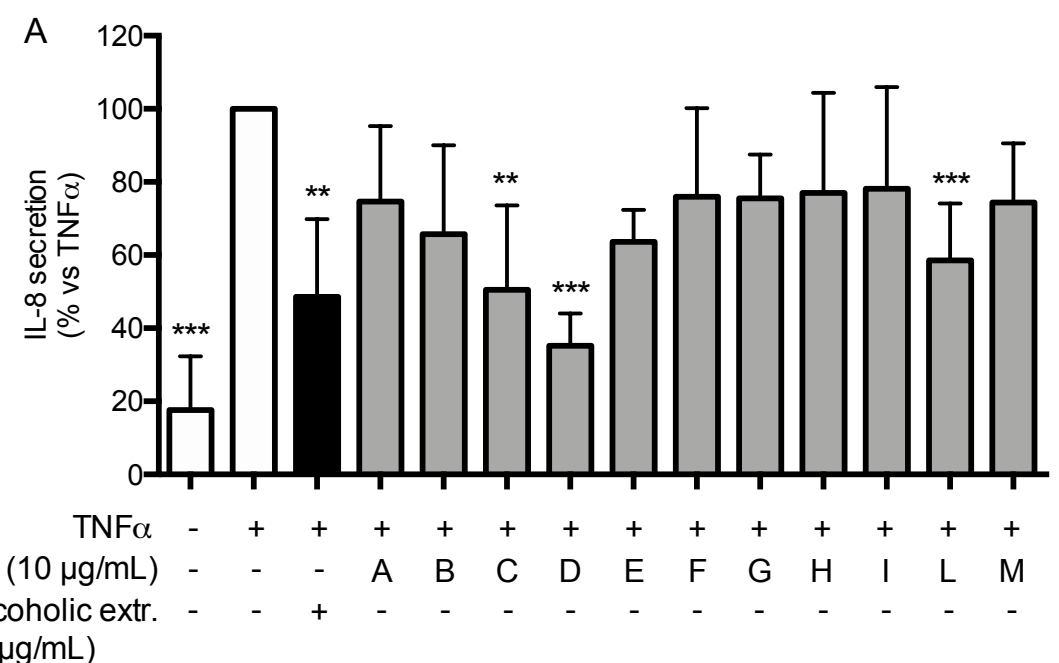

$(10 \mu \mathrm{g} / \mathrm{mL})$
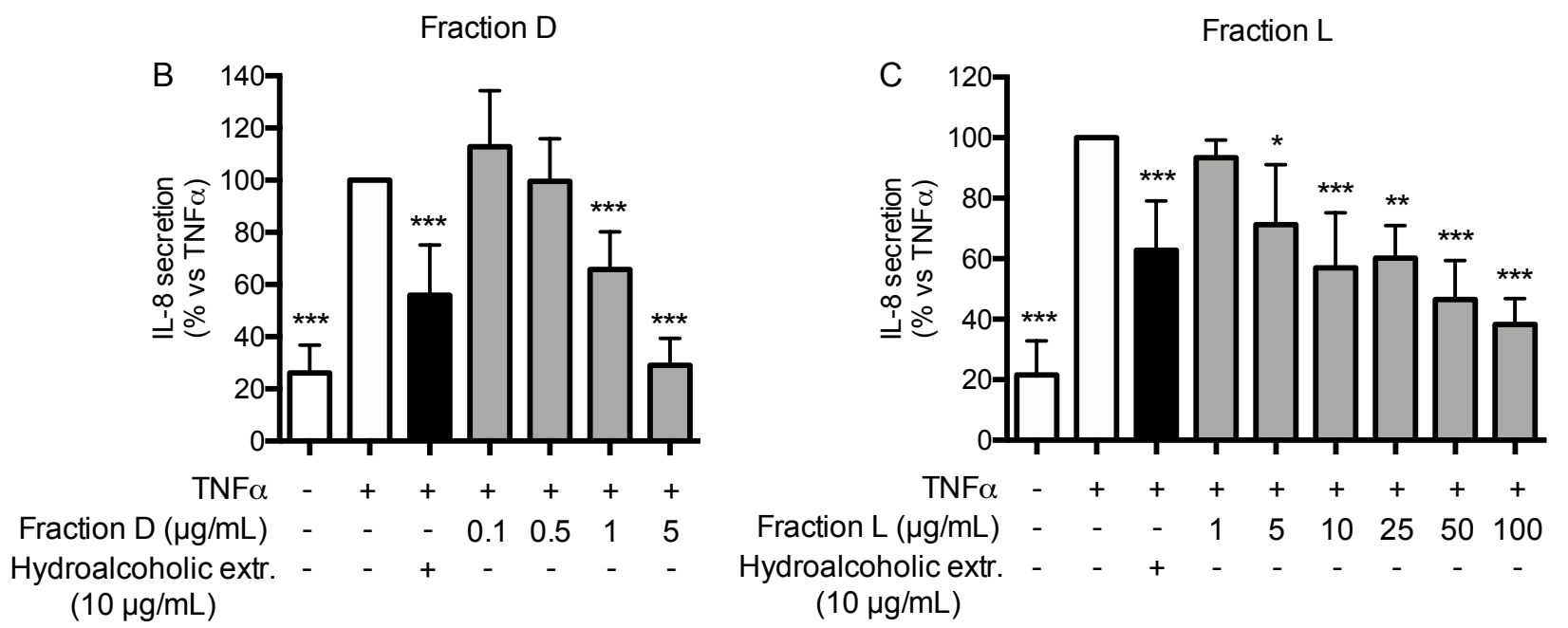

Figure 6. Inhibitory effect of the 11 fractions of the hydroalcoholic extract from hop screened at 10 $\mu \mathrm{g} / \mathrm{mL}$ on IL-8 secretion induced by TNF $\alpha$ in gastric epithelial cells (A). Evaluation of the effect of fraction $\mathrm{D}(\mathrm{B})$ and fraction $\mathrm{L}(\mathrm{C})$ in the same experimental setting. Results are expressed as percentage of the TNF $\alpha$ stimulated condition. The hydroalcoholic extract $(10 \mu \mathrm{g} / \mathrm{mL})$ was used as positive control.

To identify the bioactive compounds, the total hydroalcoholic extract was fractionated by silica gel column chromatography affording 11 fractions, which were tested for their ability to impair IL-8 release. The analysis on the fractions revealed that only three fractions, C, D and, in much lesser extent, L, significantly inhibited the secretion (Figure 6A). Considering that fraction $\mathrm{C}$ and $\mathrm{D}$, given their consecutive elution, most likely contain similar compounds, we tested the effect of fraction D, the most active, and L at different concentrations in the same model. Fraction D (Figure 6B), in agreement with preliminary screening, showed higher effect compared to fraction L (Figure 6C) with 
an $\mathrm{IC}_{50}$ more than six times lower $\left(\mathrm{IC}_{50}\right.$ of $1.93 \mu \mathrm{g} / \mathrm{mL}$ and $12.41 \mu \mathrm{g} / \mathrm{mL}$, respectively). HPLC purification of fraction $\mathrm{D}$ revealed that this fraction was mainly composed by xanthohumol $\mathrm{A}$, but it also contained minor amounts (about $10 \%$ ) of xanthohumol D. These compounds were identified on the basis of the comparison of their ${ }^{1} \mathrm{H}$ NMR spectra with those reported in the literature (Kupse \& Erhardt, 2007; Nookandeh et al., 2004).

These molecules were purified and separately evaluated on IL-8 secretion (Figure 7A and 7B) and both were able to reduce this parameter, but not to completely inhibit the secretion even at the highest concentration tested of $50 \mu \mathrm{M}$. Considering $50 \mu \mathrm{g} / \mathrm{mL}$ of the hydroalcoholic extract, only xanthohumol A reached a concentration of micromolar level, making this molecule capable of contributing to the biological activity. These results suggest otherwise that other molecules could participate in the biological activity of the extract and we cannot exclude that very minor components of the fraction D could significantly contribute to its activity. Hop prenylflavonoids are efficiently extracted by hydroalcoholic solutions (Biendl M 2013), thus explaining why hydroalcoholic are more active than aqueous extracts.
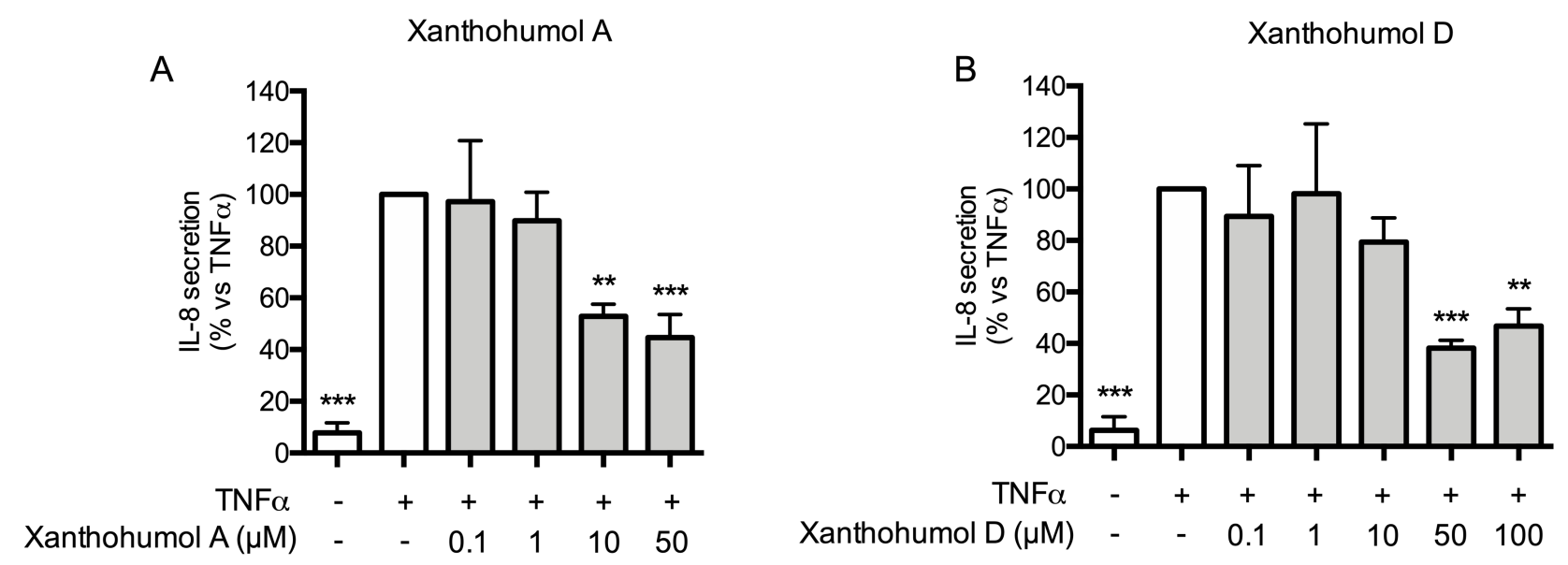

Figure 7. A: Inhibitory effect of the xanthohumol A (A) in comparison to xanthohumol D (B) on IL8 secretion induced by TNFa in gastric epithelial cells. Results are expressed as percentage of the TNF $\alpha$ stimulated condition. EGCG $(10 \mu \mathrm{M})$ and curcumin $(10 \mu \mathrm{M})$ were used as reference inhibitors of IL-8 secretion (50\% and $81 \%$ inhibition, respectively).

To the best of our knowledge, this is the first study demonstrating the anti-inflammatory activity of xanthohumol D in human gastric epithelial cells. Many literature studies have investigated the biological properties of xanthohumol A, which is mostly known for its anti-proliferative activity in different cancer cell lines, including gastric cells (Wei et al., 2018). 
According to the literature, the effect of xanthohumol A on IL-8 was investigated in non-gastric cell lines, such as pancreatic adenocarcinoma cells (Saito et al., 2018) and hepatic carcinoma cells (Dorn, Weiss, Heilmann, \& Hellerbrand, 2010), and in both cases the effect was partially mediated by NF$\kappa \mathrm{B}$ inhibition. The different concentrations of the hydroalcoholic extract required to inhibit NF- $\kappa \mathrm{B}$ and IL-8 could be explained by the multilevel control mechanism of this chemokine. IL- 8 gene in human cells is controlled by different transcription factors such as NF- $\mathrm{B}$, NF-IL6, nuclear factor- $\kappa \mathrm{B}$ repressing factor (NRF) and Activator protein 1 (AP-1) (Jundi \& Greene, 2015; Matsusaka et al., 1993; K. Yasumoto et al., 1992). Furthermore, IL-8 mRNA is stabilized by the activity of p38 mitogen-activated protein kinase (p38 MAPK) (Jundi \& Greene, 2015). Activation of NF- $\kappa B$ is known to be regulated by reactive oxygen species (ROS) and xanthohumol A may act in opposite directions in this context. In fact this molecule causes in vitro the overproduction of ROS, targeting the mitochondrial complex I, a mechanism which is involved in apoptosis of cancer cells (Zhang, Chu, Wei, Liu, \& Wei, 2015), but it also induces the transcription of cellular antioxidant enzymes through the modulation of nuclear factor (erythroid-derived 2)-like 2 (NRF2), in different cellular models (Krajka-Kuzniak, Paluszczak, \& Baer-Dubowska, 2013; Lee et al., 2011; Yao, Zhang, Ge, Peng, \& Fang, 2015).

\section{Conclusion}

Despite the mechanism of action has not been fully clarified, the hydroalcoholic extract investigated in the present study, in particular fraction $\mathrm{D}$, showed a positive effect in the downregulation of IL-8 secretion, in particular acting on the NF- $\mathrm{B}$ pathway. This effect could be partially explained by the prenylated chalcones content, especially xanthohumol A and xanthohumol D, however the contribution of other molecules to the biological activity cannot be excluded.

Our findings demonstrate that the hydroalcoholic extract of cv. Cascade hop may potentially inhibit the inflammatory reaction at gastric level, although further investigations are needed in order to better clarify contribution of other compounds in the biological activity and their mechanism of action.

\section{Acknowledgments}

The Authors would like to thank the farm "La Morosina" (Abbiategrasso, Milan, Italy) for kindly providing the starting hop material, and Dr. T. Shimohata and Prof. A. Takahashi, University of Tokushima, Japan for IL-8 promoter construct. This research was supported by grants from MIUR "Progetto Eccellenza".

\section{Declaration of interest}


Declarations of interest: none.

\section{References}

Barkett, M., \& Gilmore, T. D. (1999). Control of apoptosis by Rel/NF-kappaB transcription factors. Oncogene, 18(49), 6910-6924. doi: 10.1038/sj.onc.1203238

Biendl, M. (2013). Isolation of Prenylflavonoids from Hops. Acta Hortic, 1010, 131-140. doi: 10.17660/ActaHortic.2013.1010.15

Bonizzi, G., \& Karin, M. (2004). The two NF-kappaB activation pathways and their role in innate and adaptive immunity. Trends Immunol, 25(6), 280-288. doi: 10.1016/j.it.2004.03.008

Bray, F., Ferlay, J., Soerjomataram, I., Siegel, R. L., Torre, L. A., \& Jemal, A. (2018). Global cancer statistics 2018: GLOBOCAN estimates of incidence and mortality worldwide for 36 cancers in 185 countries. CA Cancer J Clin. doi: 10.3322/caac.21492

Bulgari, M., Sangiovanni, E., Colombo, E., Maschi, O., Caruso, D., Bosisio, E., \& Dell'Agli, M. (2012). Inhibition of neutrophil elastase and metalloprotease-9 of human adenocarcinoma gastric cells by chamomile (Matricaria recutita L.) infusion. Phytotherapy research : PTR, 26, 1817-1822. doi: 10.1002/ptr.4657

Cermak, P., Paleckova, V., Houska, M., Strohalm, J., Novotna, P., Mikyska, A., . . Sikorova, M. (2015). Inhibitory Effects of Fresh Hops on Helicobacter pylori Strains. Czech Journal of Food Sciences, 33(4), 302-307. doi: 10.17221/261/2014-Cjfs

Chen, X. Z., Schottker, B., Castro, F. A., Chen, H., Zhang, Y., Holleczek, B., \& Brenner, H. (2016). Association of helicobacter pylori infection and chronic atrophic gastritis with risk of colonic, pancreatic and gastric cancer: A ten-year follow-up of the ESTHER cohort study. Oncotarget, 7(13), 17182-17193. doi: 10.18632/oncotarget.7946

Cho, Y. C., Kim, H. J., Kim, Y. J., Lee, K. Y., Choi, H. J., Lee, I. S., \& Kang, B. Y. (2008). Differential anti-inflammatory pathway by xanthohumol in IFN-gamma and LPS-activated macrophages. International Immunopharmacology, 8(4), 567-573. doi: 10.1016/j.intimp.2007.12.017

Choi, S. C., Choi, E. J., Oh, H. M., Lee, S., Lee, J. K., Lee, M. S., . . Jun, C. D. (2006). DA-9601, a standardized extract of Artemisia asiatica, blocks TNF-alpha-induced IL-8 and CCL20 production by inhibiting p38 kinase and NF-kappaB pathways in human gastric epithelial cells. [Research Support, Non-U.S. Gov't]. World J Gastroenterol, 12(30), 4850-4858. 
Chuah, S. K., Wu, D. C., Suzuki, H., Goh, K. L., Kao, J., \& Ren, J. L. (2014). Peptic ulcer diseases: genetics, mechanism, and therapies. Biomed Res Int, 2014, 898349. doi: $10.1155 / 2014 / 898349$

Crabtree, J. E. (1996). Gastric mucosal inflammatory responses to Helicobacter pylori. Aliment Pharmacol Ther, 10 Suppl 1, 29-37.

Crabtree, J. E., Farmery, S. M., Lindley, I. J., Figura, N., Peichl, P., \& Tompkins, D. S. (1994). CagA/cytotoxic strains of Helicobacter pylori and interleukin-8 in gastric epithelial cell lines. J Clin Pathol, 47(10), 945-950.

Crabtree, J. E., Shallcross, T. M., Heatley, R. V., \& Wyatt, J. I. (1991). Mucosal tumour necrosis factor alpha and interleukin-6 in patients with Helicobacter pylori associated gastritis. [Research Support, Non-U.S. Gov't]. Gut, 32(12), 1473-1477.

de Gaetano, G., Costanzo, S., Di Castelnuovo, A., Badimon, L., Bejko, D., Alkerwi, A., .. Iacoviello, L. (2016). Effects of moderate beer consumption on health and disease: A consensus document. Nutr Metab Cardiovasc Dis, 26(6), 443-467. doi: 10.1016/j.numecd.2016.03.007

Dorn, C., Heilmann, J., \& Hellerbrand, C. (2012). Xanthohumol Suppresses Hepatic Inflammatory Response to Acute Liver Injury. Journal of Hepatology, 56, S72-S72.

Dorn, C., Kraus, B., Motyl, M., Weiss, T. S., Gehrig, M., Scholmerich, J., . . Hellerbrand, C. (2010). Xanthohumol, a chalcon derived from hops, inhibits hepatic inflammation and fibrosis. Molecular Nutrition \& Food Research, 54, S205-S213. doi: 10.1002/mnfr.200900314

Dorn, C., Weiss, T. S., Heilmann, J., \& Hellerbrand, C. (2010). Xanthohumol, a prenylated chalcone derived from hops, inhibits proliferation, migration and interleukin- 8 expression of hepatocellular carcinoma cells. Int J Oncol, 36(2), 435-441.

Forino, M., Pace, S., Chianese, G., Santagostini, L., Werner, M., Weinigel, C., . . . TaglialatelaScafati, O. (2016). Humudifucol and Bioactive Prenylated Polyphenols from Hops (Humulus lupulus cv. "Cascade"). J Nat Prod, 79(3), 590-597. doi: 10.1021/acs.jnatprod.5b01052

Fumagalli, M., Sangiovanni, E., Vrhovsek, U., Piazza, S., Colombo, E., Gasperotti, M., ... Dell'Agli, M. (2016). Strawberry tannins inhibit IL-8 secretion in a cell model of gastric inflammation. Pharmacol Res, 111, 703-712. doi: 10.1016/j.phrs.2016.07.028

Gionchetti, P., Vaira, D., Campieri, M., Holton, J., Menegatti, M., Belluzzi, A., . . et al. (1994). Enhanced mucosal interleukin-6 and -8 in Helicobacter pylori-positive dyspeptic patients. Am J Gastroenterol, 89(6), 883-887.

Jundi, K., \& Greene, C. M. (2015). Transcription of Interleukin-8: How Altered Regulation Can Affect Cystic Fibrosis Lung Disease. Biomolecules, 5(3), 1386-1398. doi: 10.3390/biom5031386 
Krajka-Kuzniak, V., Paluszczak, J., \& Baer-Dubowska, W. (2013). Xanthohumol induces phase II enzymes via Nrf2 in human hepatocytes in vitro. Toxicol In Vitro, 27(1), 149-156. doi: 10.1016/j.tiv.2012.10.008

Kurasawa, T., Chikaraishi, Y., Naito, A., Toyoda, Y., \& Notsu, Y. (2005). Effect of humulus lupulus on gastric secretion in a rat pylorus-ligated model. Biological \& Pharmaceutical Bulletin, 28(2), 353-357. doi: DOI 10.1248/bpb.28.353

Kupse, R. S., Erhardt, P. W. (2007). Total synthesis of xanthohumol. J Nat Prod, 70, 1507-1509. doi: 10.1021/np070158y.

Lee, I. S., Lim, J., Gal, J., Kang, J. C., Kim, H. J., Kang, B. Y., \& Choi, H. J. (2011). Antiinflammatory activity of xanthohumol involves heme oxygenase-1 induction via NRF2-ARE signaling in microglial BV2 cells. Neurochemistry International, 58(2), 153-160. doi: 10.1016/j.neuint.2010.11.008

Li, H-J.; Deinzer, M.L. (2007). Tandem mass spectrometry for sequencing proanthocyanidins. Anal Chem 79, 1739-1748. doi: 10.1021/ac061823v

Magalhaes PJ, Vieira JS, Goncalves LM, Pacheco JG, Guido LF, Barros AA. (2010). Isolation of phenolic compounds from hop extracts using polyvinylpyrrolidone: characterization by highperformance liquid chromatography-diode array detection-electrospray tandem mass spectrometry. J Chrom A 1217, 3258-3268. doi: 10.1016/j.chroma.2009.10.068

Matsusaka, T., Fujikawa, K., Nishio, Y., Mukaida, N., Matsushima, K., Kishimoto, T., \& Akira, S. (1993). Transcription factors NF-IL6 and NF-kappa B synergistically activate transcription of the inflammatory cytokines, interleukin 6 and interleukin 8. Proc Natl Acad Sci U S A, 90(21), 10193-10197.

Moss, S. F., Legon, S., Davies, J., \& Calam, J. (1994). Cytokine gene expression in Helicobacter pylori associated antral gastritis. Gut, 35(11), 1567-1570.

Noach, L. A., Bosma, N. B., Jansen, J., Hoek, F. J., van Deventer, S. J., \& Tytgat, G. N. (1994). Mucosal tumor necrosis factor-alpha, interleukin-1 beta, and interleukin- 8 production in patients with Helicobacter pylori infection. Scand J Gastroenterol, 29(5), 425-429.

Nookandeh, A., Frank, N., Steiner, F., Ellinger, R.,Schneider, B., Gerhauser, C., Becker, C. (2004) Xanthohumol metabolites in faeces of rats. Phytochemistry, 65, 561-570. doi: 10.1016/j.phytochem.2003.11.016.

Ohata, H., Kitauchi, S., Yoshimura, N., Mugitani, K., Iwane, M., Nakamura, H., . . Ichinose, M. (2004). Progression of chronic atrophic gastritis associated with Helicobacter pylori infection increases risk of gastric cancer. Int J Cancer, 109(1), 138-143. doi: 10.1002/ijc.11680 
Rugge, M., Pennelli, G., Pilozzi, E., Fassan, M., Ingravallo, G., Russo, V. M., \& Di Mario, F. (2011). Gastritis: the histology report. Digestive and liver disease : official journal of the Italian Society of Gastroenterology and the Italian Association for the Study of the Liver, 43 Suppl 4, S373-384. doi: 10.1016/S1590-8658(11)60593-8

Saito, K., Matsuo, Y., Imafuji, H., Okubo, T., Maeda, Y., Sato, T., . . . Takiguchi, S. (2018). Xanthohumol inhibits angiogenesis by suppressing nuclear factor-kappaB activation in pancreatic cancer. Cancer Sci, 109(1), 132-140. doi: 10.1111/cas.13441

Sangiovanni, E., Di Lorenzo, C., Colombo, E., Colombo, F., Fumagalli, M., Frigerio, G., . . . Dell'Agli, M. (2015). The effect of in vitro gastrointestinal digestion on the anti-inflammatory activity of Vitis vinifera L. leaves. Food Funct. doi: 10.1039/c5fo00410a

Sharma, S. A., Tummuru, M. K., Miller, G. G., \& Blaser, M. J. (1995). Interleukin-8 response of gastric epithelial cell lines to Helicobacter pylori stimulation in vitro. Infect Immun, 63(5), 1681-1687.

Shishodia, S., \& Aggarwal, B. B. (2004). Nuclear factor-kappaB: a friend or a foe in cancer? Biochem Pharmacol, 68(6), 1071-1080. doi: 10.1016/j.bcp.2004.04.026

Siregar, G. A., Halim, S., \& Sitepu, V. R. (2015). Serum TNF-a, IL-8, VEGF levels in Helicobacter pylori infection and their association with degree of gastritis. Acta Med Indones, 47(2), 120126.

Tripp, M., Darland, G., Lerman, R., Lukaczer, D., Bland, J., \& Babish, J. (2005). Hop and modified hop extracts have potent in vitro anti-inflammatory properties. Proceedings of the 1 st International Humulus Symposium(668), 217-227. doi: DOI 10.17660/ActaHortic.2005.668.28

Wei, S., Sun, T., Du, J., Zhang, B., Xiang, D., \& Li, W. (2018). Xanthohumol, a prenylated flavonoid from Hops, exerts anticancer effects against gastric cancer in vitro. Oncol Rep. doi: 10.3892/or.2018.6723

Xuan, J., Deguchi, R., Yanagi, H., Ozawa, H., Urano, T., Ogawa, Y., . . . Takagi, A. (2005). Relationship between gastric mucosal IL-8 levels and histological gastritis in patients with Helicobacter pylori infection. Tokai J Exp Clin Med, 30(2), 83-88.

Yahiro, K., Shirasaka, D., Tagashira, M., Wada, A., Morinaga, N., Kuroda, F., . . Noda, M. (2005). Inhibitory effects of polyphenols on gastric injury by Helicobacter pylori VacA toxin. Helicobacter, 10(3), 231-239. doi: 10.1111/j.1523-5378.2005.00315.x

Yao, J., Zhang, B., Ge, C., Peng, S., \& Fang, J. (2015). Xanthohumol, a polyphenol chalcone present in hops, activating Nrf2 enzymes to confer protection against oxidative damage in PC12 cells. J Agric Food Chem, 63(5), 1521-1531. doi: 10.1021/jf505075n 
Yasumoto, K., Okamoto, S., Mukaida, N., Murakami, S., Mai, M., \& Matsushima, K. (1992). Tumor necrosis factor alpha and interferon gamma synergistically induce interleukin 8 production in a human gastric cancer cell line through acting concurrently on AP-1 and NF-kB-like binding sites of the interleukin 8 gene. $J$ Biol Chem, 267(31), 22506-22511.

Yasumoto, K., Okamoto, S., Mukaida, N., Murakami, S., Mai, M., \& Matsushima, K. (1992). Tumor necrosis factor alpha and interferon gamma synergistically induce interleukin 8 production in a human gastric cancer cell line through acting concurrently on AP-1 and NF-kB-like binding sites of the interleukin 8 gene. The Journal of biological chemistry, 267, 22506-22511.

Zhang, B., Chu, W., Wei, P., Liu, Y., \& Wei, T. T. (2015). Xanthohumol induces generation of reactive oxygen species and triggers apoptosis through inhibition of mitochondrial electron transfer chain complex I. Free Radical Biology and Medicine, 89, 486-497. doi: 10.1016/j.freeradbiomed.2015.09.021 